\title{
Transcatheter aortic valve implantation: initial experience in Hong Kong
}

\author{
Michael KY Lee *, SF Chui, Alan KC Chan, Jason LK Chan, Eric CY Wong, KT Chan, \\ HL Cheung, CS Chiang
}

- A video clip showing transcatheter aortic valve implantation technique is available at $<w w w$. hkmj.org>

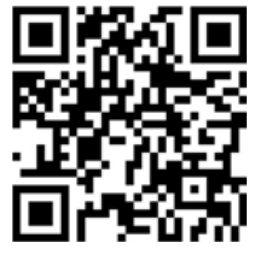

This article was published on 28 Jun 2017 at www.hkmj.org.

\section{A B S T R A C T}

Introduction: Aortic stenosis is one of the most common valvular heart diseases in the ageing population. Patients with symptomatic severe aortic stenosis are at high risk of sudden death. Surgical aortic-valve replacement is the gold standard of treatment but many patients do not receive surgery because of advanced age or co-morbidities. Recently, transcatheter aortic valve implantation has been developed as an option for these patients. This study aimed to assess efficacy and safety of this procedure in the Hong Kong Chinese population.

Methods: Data for baseline patient characteristics, procedure parameters, and clinical outcomes up to 1 -year post-implantation in a regional hospital in Hong Kong were collected and analysed.

Results: A total of 56 patients with severe aortic stenosis underwent the procedure from December 2010 to September 2015. Their mean ( \pm standard deviation) age was $81.9 \pm 4.8$ years; $64.3 \%$ of them were male. Their mean logistic EuroSCORE was $22.6 \% \pm 13.4 \%$. After implantation, the mean aortic valve area improved from $0.70 \mathrm{~cm}^{2} \pm 0.19 \mathrm{~cm}^{2}$ to $1.94 \mathrm{~cm}^{2} \pm 0.37 \mathrm{~cm}^{2}$. Of the patients, $92 \%$ were improved by at least one New York Heart Association functional class. Stroke and major vascular complications occurred in one (1.8\%) and five (8.9\%)

patients, respectively. A permanent pacemaker was implanted in seven (12.5\%) patients. Both hospital and 30 -day mortalities were $1.8 \%$. The 1 -year allcause and cardiovascular mortality rates were $12.5 \%$ and $7.1 \%$, respectively.

Conclusions: Transcatheter aortic valve implantation has been developed as an alternative treatment for patients with symptomatic severe aortic stenosis who are deemed inoperable or high risk for surgery. Our results are very promising and comparable with those of major clinical trials.

\section{Hong Kong Med J 2017;23:349-55} DOI: $10.12809 / \mathrm{hkmj} 166030$

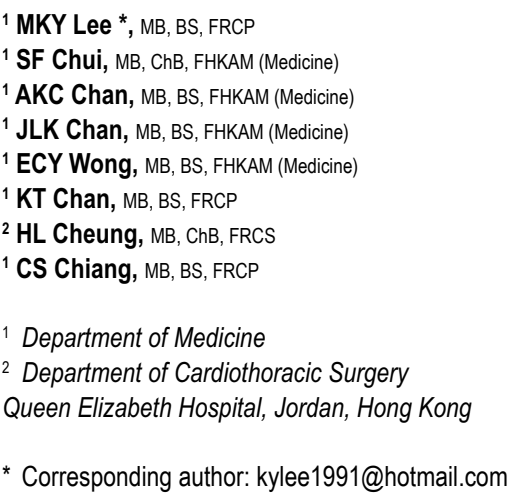

New knowledge added by this stud

- Transcatheter aortic valve implantation (TAVI) is safe and feasible in patients with symptomatic severe aortic valve stenosis and high surgical risk.

- Clinical outcome was very promising for up to 1 year in patients who underwent TAVI.

Implications for clinical practice or policy

- TAVI should be offered to patients with symptomatic severe aortic stenosis who are deemed inoperable or at high risk for open heart surgery.

\section{Introduction}

With improved living standards and advances in medical treatment, the respective life expectancies of males and females in Hong Kong have increased from 72.3 years and 78.5 years in 1981 , to 81.2 years and 86.7 years in $2014 .^{1}$ Aortic stenosis is one of the most common valvular heart diseases in the ageing population. ${ }^{2}$ The prevalence of aortic stenosis is up to $4.6 \%$ in people older than 75 years. ${ }^{2}$ After onset of symptoms, including the classic triad of chest pain, heart failure or syncope, patients with severe aortic stenosis are at very high risk of sudden death with 2-year mortality rate of up to $50 \%$ if left untreated. ${ }^{3-5}$ Surgical aortic-valve replacement (SAVR) is the gold standard of treatment for patients with symptomatic severe aortic stenosis. ${ }^{3,4,6,7}$ Many do not receive surgical treatment, however, because of advanced age or multiple co-morbidities. ${ }^{8}$ Transcatheter aortic valve implantation (TAVI) has recently been developed as an option for these patients who are inoperable or at high risk of SAVR. ${ }^{9,10}$

Queen Elizabeth Hospital is the first hospital 


\section{經導管主動脈瓣植入術：香港的初期經驗 \\ 李耿淵、徐城烽、陳家俊、陳良貴、黃志遠、陳鑑添、 張鴻亮、蔣忠想}

引言：随着人口老化, 主動脈瓣狹窄是其中一種最常見的心臟瓣膜疾 病。一旦出現症狀, 嚴重主動脈瓣狹窄患者的突然死亡風險會很高。

不少患者因高齡或其他疾病未能接受作為治療標準的開胸外科主動脈 瓣置換術。最近, 經導管主動脈瓣植入術 ( TAVI ) 的發展開始成熟, 為這些患者提供手術以外的選擇。本研究旨在分析TAVI對香港華籍病 人的效用及安全性。

方法：收集和分析在香港一所分區醫院內接受TAVI病人的基線特徵、 手術過程參數和術後 1 年的臨床結果數據。

結果：2010年12月至2015年9月期間, 共有56名患有嚴重主動 脈瓣狹窄的病人接受TAVI手術。患者平均 $( \pm$ 標準差 $)$ 年齡為 $81.9 \pm$ 4.8 歲; 其中 $64.3 \%$ 為男性。平均logistic EuroSCORE為 $22.6 \% \pm$ $13.4 \%$ 。接受 TAVI後, 平均主動脈瓣面積從 $0.70 \mathrm{~cm}^{2} \pm 0.19 \mathrm{~cm}^{2}$ 提升 至 $1.94 \mathrm{~cm}^{2} \pm 0.37 \mathrm{~cm}^{2} \circ 92 \%$ 的患者在紐約心臟協會（NYHA）的功 能分級中至少改善一個等級。中風和與血管有關的併發症分別有 1 例 $(1.8 \%)$ 和5例 $(8.9 \%) \circ 7$ 位 $(12.5 \%)$ 患者須植入永久性起搏器。 住院和 30 天死亡率均為 $1.8 \%$ 。術後 1 年的全因死亡率為 $12.5 \%$, 與心 血管有關的死亡率則為 $7.1 \%$ 。

結論：對於患有嚴重主動脈瓣狹窄而傳統開胸手術風險高或不適合進 行手術的病人, TAVI已發展為一種可行的治療。本研究所得的數據結 果令人非常鼓舞, 亦與外國大型臨床試驗結果相若。

in Hong Kong to perform TAVI since December 2010. This study aimed to assess the efficacy and safety of this procedure in the Hong Kong Chinese population.

\section{Methods}

In order to introduce TAVI into Hong Kong, a Structural Heart Team comprising cardiologists, cardiac surgeons, cardiac anaesthesiologists, radiologists and cardiac nurses, was formed in early 2010 in Queen Elizabeth Hospital, which is a regional hospital in Hong Kong. All potential patients were assessed and interviewed independently by cardiologists and cardiac surgeons. Clinical assessment of functional status, transthoracic echocardiogram, transoesophageal echocardiogram (TEE), computed tomographic (CT) scan, and conventional angiogram were performed according to the protocol to assess the risks of SAVR and suitability for TAVI. The Structural Heart Team would undertake these investigations to assess whether the risks of the patients were too high for SAVR and if they were suitable for TAVI.

The correct size of the TAVI device was based on the aortic annular dimensions measured by TEE and CT scan. The preferred route of device introduction was via the femoral artery. Based on findings such as the vessel diameter, degree of calcification and tortuosity found on CT imaging, the subclavian artery or direct aortic approach was also a valid alternative. The device was implanted under fluoroscopic guidance and the correct position monitored by fluoroscopy and TEE. Patients underwent transthoracic echocardiogram prior to discharge to assess device function and exclude pericardial effusion. Post-discharge, regular clinic visits, and serial transthoracic echocardiograms were arranged to assess progress and monitor any adverse events. All complications were reported to an independent Safety Monitoring Committee of the hospital.

The first TAVI device was used in December 2010 and was a self-expanding Medtronic CoreValve device (Medtronic, Minneapolis [MN], US) [Fig 1a]. Subsequent to the introduction of its secondgeneration Evolut R (Medtronic, Minneapolis [MN], US) in 2015 (Fig 1b), it was used in most cases due to its improved design of recapture/repositioning ability and its smaller sheath size (18 Fr vs $14 \mathrm{Fr}$ ). We obtained another self-expanding device with recapture/repositioning ability (St Jude Medical Portico; St Jude Medical, Minneapolis [MN], US; Fig 1c), and a balloon-expandable device (Edwards SAPIEN XT; Edwards Lifesciences, Irvine [CA], US) [Figs $1 \mathrm{~d}$ and $1 \mathrm{e}$ ] in 2015 . This enhanced the ability to (a)

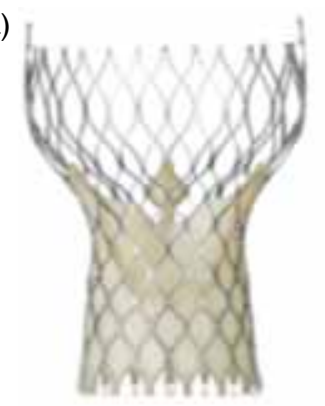

(b)

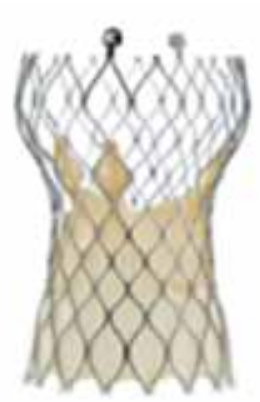

(c)

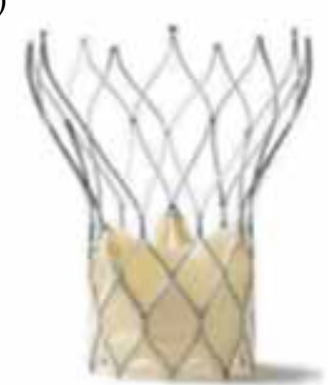

(d)

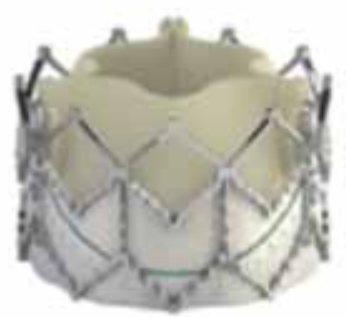

(e)

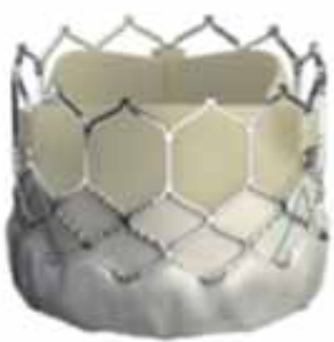

FIG I. Transcatheter aortic valve implantation device (reproduced with permission) (a) CoreValve, (b) Evolut R, (c) Portico, (d) SAPIEN XT, (e) SAPIEN S3 
treat a broad spectrum of patients with a wide variety of clinical and anatomical challenges. The choice of valve type was made by the Structural Heart Team, based on the anatomy of the native aortic valve, size, and calcification of iliofemoral vessels and need for alternative access.

All patients who underwent TAVI during the study period were entered into the TAVI registry of our hospital. Their baseline characteristics, procedural details, device used, and clinical outcomes were recorded. They attended for regular follow-up in our structural heart disease clinic as well as regular echocardiographic monitoring. Follow-up data were also added to the registry. Any patient who defaulted follow-up was contacted; if they had died, cause of death was retrieved from their electronic patient record of Hospital Authority of Hong Kong.

We retrieved and analysed the data of the TAVI registry. Descriptive statistics were used to report baseline characteristics, procedural results, and clinical outcomes. Analysis was performed using the Microsoft Office Excel (Mac version 2011; Microsoft, Washington, US). The study was performed in accordance with the principles outlined in the Declaration of Helsinki.

\section{Results}

\section{Baseline characteristics}

From December 2010 to September 2015, a total of 56 patients with symptomatic severe aortic stenosis underwent TAVI. Their baseline characteristics are outlined in Table 1 . Their mean ( \pm standard deviation) age was $81.9 \pm 4.8$ years, and the majority $(64.3 \%)$ were male. The prevalence of severe comorbidities was predicted as high, with a mean logistic EuroSCORE of $22.6 \% \pm 13.4 \%$ and a mean Society of Thoracic Surgeons score of 7.0 \pm 4.4 . Several variables were taken into account when calculating these risk scores, such as age, symptoms at presentation, current haemodynamic status, left ventricular systolic function, baseline renal function, New York Heart Association (NYHA) functional class, and presence of other co-morbidities such as peripheral artery disease, pulmonary disease, and cerebrovascular disease. The mean left ventricular ejection fraction (LVEF) was 54.8\% \pm $12.9 \%$. Most patients had various degrees of heart failure symptoms with 22 (39.3\%), 26 (46.4\%), and six $(10.7 \%)$ patients in NYHA class II, III, and IV, respectively. All patients had severe aortic stenosis on echocardiography, defined by standard criteria with a mean aortic valve area of $0.7 \mathrm{~cm}^{2} \pm 0.2 \mathrm{~cm}^{2}$ and mean aortic transvalvular pressure gradient of $49.0 \mathrm{~mm} \mathrm{Hg} \pm 12.9 \mathrm{~mm} \mathrm{Hg}$.

\section{Procedural outcomes}

The procedural outcomes are summarised in Table
TABLE I. Baseline characteristics $(n=56)$

\begin{tabular}{|c|c|}
\hline Characteristic & $\begin{array}{c}\text { Mean } \pm \text { SD or } \\
\text { No. (\%) of patients }\end{array}$ \\
\hline Age (years) & $81.9 \pm 4.8$ \\
\hline Male & $36(64.3)$ \\
\hline Diabetes & $10(17.9)$ \\
\hline Hypertension & $24(42.9)$ \\
\hline Creatinine $(\mu \mathrm{mol} / \mathrm{L})$ & $125.2 \pm 75.2$ \\
\hline Chronic renal failure ${ }^{*}$ & $18(32.1)$ \\
\hline Previous stroke & $4(7.1)$ \\
\hline Coronary artery disease & $44(78.6)$ \\
\hline Previous myocardial infarction & $16(28.6)$ \\
\hline Peripheral vascular disease & $9(16.1)$ \\
\hline Chronic obstructive pulmonary disease & $8(14.3)$ \\
\hline \multicolumn{2}{|l|}{ NYHA functional class } \\
\hline 1 & $2(3.6)$ \\
\hline II & $22(39.3)$ \\
\hline III & $26(46.4)$ \\
\hline IV & $6(10.7)$ \\
\hline Left ventricular ejection fraction (\%) & $54.8 \pm 12.9$ \\
\hline Aortic orifice area $\left(\mathrm{cm}^{2}\right)$ & $0.7 \pm 0.2$ \\
\hline $\begin{array}{l}\text { Aortic transvalvular pressure gradient } \\
(\mathrm{mm} \mathrm{Hg})\end{array}$ & $49.0 \pm 12.9$ \\
\hline \multicolumn{2}{|l|}{ Aortic regurgitation } \\
\hline Nil or trivial & $17(30.4)$ \\
\hline Mild & $28(50.0)$ \\
\hline Moderate or above & $11(19.6)$ \\
\hline \multicolumn{2}{|l|}{ Mitral regurgitation } \\
\hline Nil or trivial & $14(25.0)$ \\
\hline Mild & $25(44.6)$ \\
\hline Moderate or above & $17(30.4)$ \\
\hline Pulmonary hypertension & $34(60.7)$ \\
\hline Logistic EuroSCORE (\%) & $22.6 \pm 13.4$ \\
\hline STS score & $7.0 \pm 4.4$ \\
\hline
\end{tabular}

2. Successful implantation was completed in $98.2 \%$ of patients and all procedures were performed under general anaesthesia. Transfemoral access was successful in most cases (54 patients, 96.4\%) although one $(1.8 \%)$ patient was treated via the subclavian approach and one (1.8\%) via a direct aortic approach. The most commonly used TAVI device was a $26-\mathrm{mm}$ prosthesis. A second valve was required during the index procedure in nine (16.1\%) patients due to suboptimal position of the first device. Most patients (32/56, 57.1\%) had no or trivial aortic regurgitation following implantation and $23(41.1 \%)$ had mild aortic regurgitation. None had moderate or severe aortic regurgitation. 
TABLE 2. Procedural outcomes $(n=56)$

\begin{tabular}{lc}
\hline Outcome & $\begin{array}{c}\text { Mean } \pm \text { SD or } \\
\text { No. (\%) of patients* }\end{array}$ \\
\hline Transfemoral & $54(96.4)$ \\
\hline Subclavian & $1(1.8)$ \\
\hline Direct aortic & $1(1.8)$ \\
\hline Successful implantation of prosthesis & $55(98.2)$ \\
\hline Annulus size by perimeter (mm) & $74.0 \pm 8.6$ \\
\hline Annulus maximal diameter (mm) & $25.8 \pm 3.4$ \\
\hline Annulus minimal diameter (mm) & $20.3 \pm 3.4$ \\
\hline Prosthesis size by diameter (mm) & \\
\hline 23 & $4(7.1)$ \\
\hline 26 & $25(44.6)$ \\
\hline 29 & $22(39.3)$ \\
\hline 31 & $5(8.9)$ \\
\hline Valve post-dilation & $18(32.1)$ \\
\hline Second valve required & $9(16.1)$ \\
\hline Post-procedural aortic regurgitation & $23(41.1)$ \\
\hline No or trivial & 0 \\
\hline Mild & \\
\hline
\end{tabular}

Abbreviation: $\mathrm{SD}=$ standard deviation

* Because of rounding, not all percentages total 100

\section{Adverse events}

The safety endpoints and clinical outcomes are outlined in Table 3. Conversion to open heart surgery after the procedure was necessary in two patients, one of whom had a calcified valvular leaflet that dislodged into the left atrium after device implantation and required open exploration. The other patient had incessant ventricular fibrillation, possibly due to coronary obstruction during the procedure, and required emergent cardiopulmonary bypass and open heart surgery. Pre-procedural $\mathrm{CT}$ revealed adequate coronary height (both left coronary and right coronary ostium $>16 \mathrm{~mm}$ above annular plane) and adequate sinus of Valsalva diameters. The coronary obstruction was thought to be due to dislodged calcified nodules from the aortic valve leaflets. This patient eventually died despite SAVR under extracorporeal membrane oxygenation support, and was the only hospital mortality (1.8\%).

Stroke occurred in one $(1.8 \%)$ patient within 30 days. New conduction abnormalities requiring permanent pacing were present in seven (12.5\%) patients. There were major access-related vascular complications in five (8.9\%) patients and three (5.4\%) had acute kidney injury stage 2 although none required long-term dialysis and no patient had acute kidney injury stage 3 (Table 3 ).
TABLE 3. Clinical and safety outcomes $(n=56)$

\begin{tabular}{|c|c|}
\hline Outcome & $\begin{array}{c}\text { No. }(\%) \text { of } \\
\text { patients }\end{array}$ \\
\hline Conversion to open heart surgery & $2(3.6)$ \\
\hline Annular rupture & 0 \\
\hline Coronary obstruction & $1(1.8)$ \\
\hline \multicolumn{2}{|l|}{ Mortality } \\
\hline In hospital & $1(1.8)$ \\
\hline 30-Day all-cause & $1(1.8)$ \\
\hline 30-Day cardiovascular & $1(1.8)$ \\
\hline 6-Month all-cause & $5(8.9)$ \\
\hline 6-Month cardiovascular & $3(5.4)$ \\
\hline $1-$ Year all-cause ${ }^{*}$ & $7(12.5)$ \\
\hline 1-Year cardiovascular* & $4(7.1)$ \\
\hline Stroke with 30 days & $1(1.8)$ \\
\hline Major bleeding & $2(3.6)$ \\
\hline Acute kidney injury: stage $2 \dagger$ & $3(5.4)$ \\
\hline Acute kidney injury: stage $3 \ddagger$ & 0 \\
\hline \multicolumn{2}{|l|}{ Vascular complications } \\
\hline Major & $5(8.9)$ \\
\hline Minor & $4(7.1)$ \\
\hline New permanent pacemaker implantation & $7(12.5)$ \\
\hline $\begin{array}{l}\text { * Of } 50 \text { patients who had transcatheter aor } \\
\text { implantation for }>\text { I year } \\
+ \text { Defined when the increase in serum creat } \\
299 \% \text { compared with the baseline or incre } \\
>0.3 \mathrm{mg} / \mathrm{dL}(>26.4 \mathrm{mmol} / \mathrm{L}) \text { and }<4.0 \mathrm{mg} \\
\neq \text { Defined when the increase in serum creat } \\
\text { compared with the baseline or serum crea } \\
\geq 4.0 \mathrm{mg} / \mathrm{dL}(\geq 354 \mathrm{mmol} / \mathrm{L}) \text { with an acute } \\
0.5 \mathrm{mg} / \mathrm{dL}(44 \mathrm{mmol} / \mathrm{L})\end{array}$ & $\begin{array}{l}\text { alve } \\
\text { is } 200 \% \text { to } \\
\text { between } \\
(<354 \mathrm{mmol} / \mathrm{L}) \\
\text { e is } \geq 300 \% \\
\text { he of } \\
\text { ease of at least }\end{array}$ \\
\hline
\end{tabular}

\section{Follow-up results}

Most patients (55/56, 98.2\%) either had regular follow-up or died. Only one patient who relocated to Mainland China was lost to follow-up, although his doctor keeps us updated regularly about his condition. The longest follow-up period was 5 years. The 30 -day mortality rate was $1.8 \%$. The NYHA functional class of patients at baseline and at 30 days is outlined in Figure 2; 92\% of patients improved by at least one functional class. The mean LVEF was $57.9 \% \pm 10.9 \%$ at 30 days. The mean aortic valve area improved to $1.94 \mathrm{~cm}^{2} \pm 0.37 \mathrm{~cm}^{2}$ and mean aortic transvalvular pressure gradient improved to $8.1 \mathrm{~mm} \mathrm{Hg} \pm 3.4 \mathrm{~mm} \mathrm{Hg}$ (Fig 3). These improvements persisted at 6-month and 1-year follow-up assessment. The 6-month all-cause and cardiovascular mortalities were $8.9 \%$ and $5.4 \%$, respectively. The 1-year all-cause and cardiovascular mortalities were $12.5 \%$ and $7.1 \%$, respectively (Table 3 ). Causes of 1-year mortality included myocardial 
infarction, heart failure with cardiogenic shock, liver failure, pneumonia, and sepsis with disseminated intravascular coagulopathy.

\section{Discussion}

This is the first report to describe the clinical experience of TAVI in a major tertiary referral hospital, which is also the first hospital in Hong Kong to introduce this technology and having the largest case volume in Hong Kong up until the end of 2015. The clinical outcomes of our cohort show very promising results.

Since 2010, there have been several landmark clinical trials describing the initial clinical outcome of TAVI in both high-surgicalrisk and inoperable patients. The PARTNER 1 was a multicentre prospective randomised controlled trial to investigate the balloon-expandable Edwards SAPIEN valve (Edwards Lifesciences). PARTNER $1 \mathrm{~B}$ arm randomised inoperable patients to TAVI or best medical treatment and showed a $20 \%$ absolute reduction in mortality rate at 1 year with TAVI. ${ }^{9}$ The PARTNER 1A arm randomised patients with high surgical risk to either TAVI or SAVR and TAVI was shown to be non-inferior to SAVR in terms of mortality rate at 1 year $(24 \%$ vs $26.8 \%$; $=0.44) .{ }^{11}$ The US CoreValve pivotal trial randomised patients with high surgical risk to either TAVI using the selfexpanding CoreValve or SAVR and demonstrated a significant reduction in mortality rate at 1 year in the TAVI group compared with the SAVR group (14.2\% vs $19.1 \%$; $\mathrm{P}=0.04) .{ }^{10}$ The relatively high 1 -year mortality rate in those clinical trials is mainly due to their baseline multiple co-morbidities and the advanced age (mean age, 80 years) of patients. The 1-year mortality rate of $12.5 \%$ in our cohort compares well with these landmark trials. The risk profile of our patient group is nonetheless not lower (logistic EuroSCORE of $22 \%$ in our group vs $18 \%$ in CoreValve pivotal trial). This high baseline risk factor accounts for the high 1-year mortality rate although a significant proportion was related to non-cardiac causes (3 out of 7). The current view is to avoid treating the patients with too high risk and who will not benefit from this high-risk procedure. A reasonable 1-year expected survival is also a prerequisite. ${ }^{12,13}$

Other complication rates of our cohort also compared well with the landmark trials. Significant aortic regurgitation secondary to paravalvular leak (PVL) is a unique problem not uncommonly encountered following TAVI in contrast to patients who undergo SAVR in whom there is usually no residual leakage. ${ }^{14,15}$ One study showed that even mild PVL after TAVI is associated with higher mortality rate at 2 years. ${ }^{16}$ Treatment of significant PVL is by post-dilation, putting in another valve (so called 'valve in valve') or using a vascular plug. The rate of

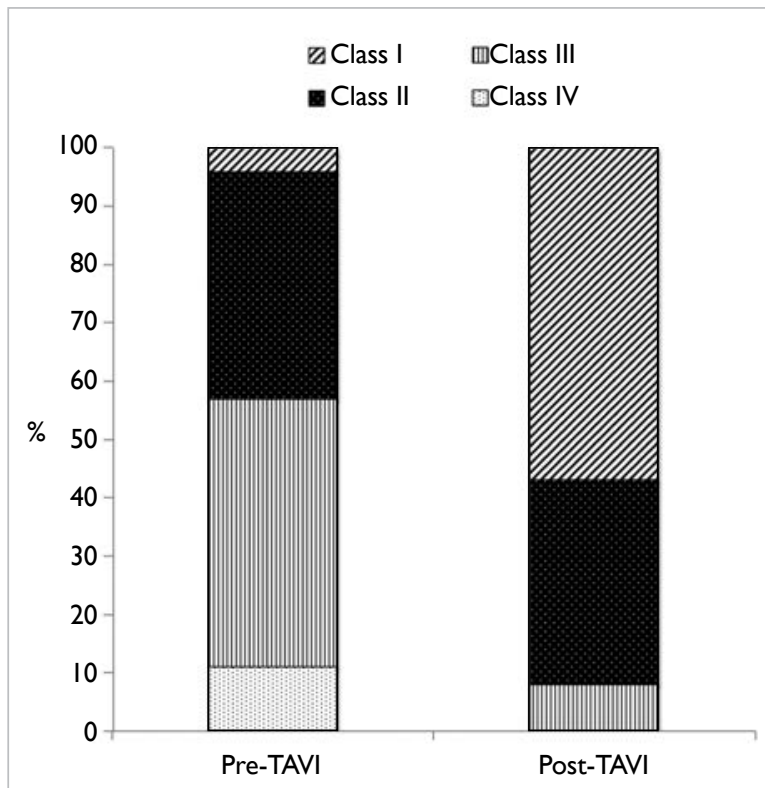

FIG 2. NYHA functional class* of patients at baseline and at 30 days

Abbreviations: NYHA = New York Heart Association; TAVI = transcatheter aortic valve implantation

* Class I: no limitation of physical activity; class II: slight limitation of physical activity; class III: marked limitation of physical activity; class IV: inability to carry out any physical activity without discomfort

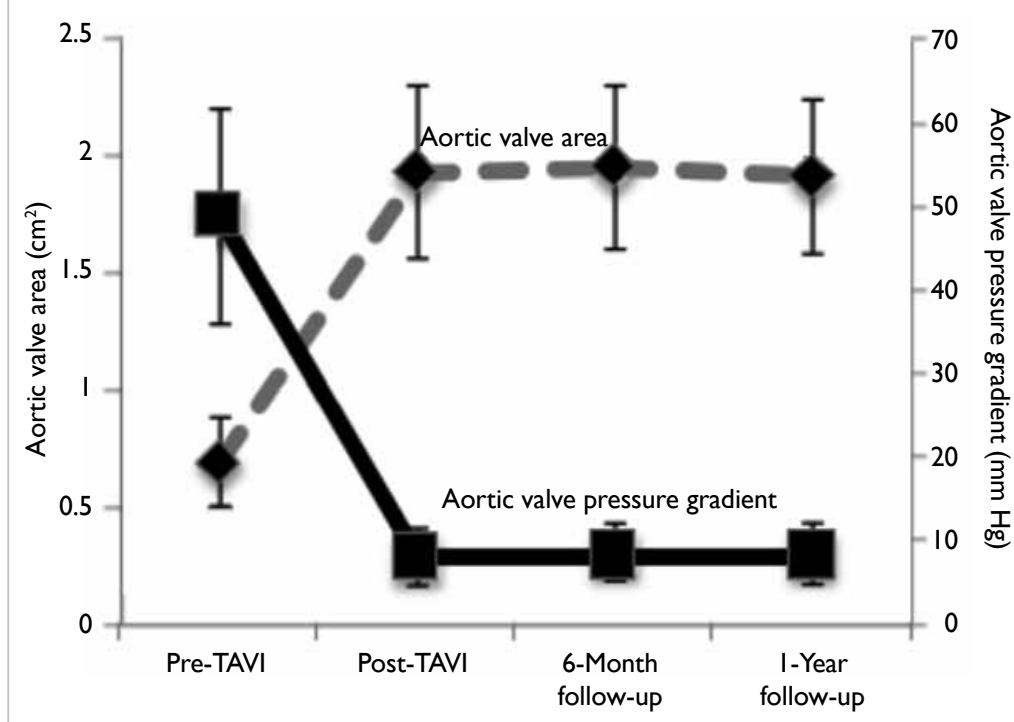

FIG 3.The mean aortic valve area and pressure gradient Error bars indicate $95 \%$ confidence intervals Abbreviation:TAVI = transcatheter aortic valve implantation

moderate or severe PVL in both the PARTNER $1 \mathrm{~B}^{9}$ and US CoreValve pivotal trial ${ }^{10}$ was approximately $7 \%$. No moderate or severe PVL was noted in our 
study due to the high rate of using two valves ('valve in valve') in $16 \%$ of our cohort compared with the reported $4 \%$ rate in the US CoreValve pivotal trial. With increasing experience and availability of a repositionable device, however, progressively fewer cases required more than one valve.

Some of the complications after TAVI are more disabling than others, such as stroke. The major stroke rate in both the PARTNER and US CoreValve pivotal trial was approximately $5 \% .{ }^{9,10}$ Major stroke rate in one meta-analysis of more than 10000 patients was $3.3 \% .^{17}$ Clinical stroke occurred in only one $(1.8 \%)$ patient in our cohort. This is probably because of our small sample size, as well as the random and unpredictable nature of this complication. More cases of stroke would be expected if more patients were treated. The latest clinical trial using next-generation TAVI devices resulted in a much lower rate of stroke after TAVI $(0.9 \%$ at 30 days and $2.4 \%$ at 1 year for high-risk patients).$^{18}$ The aetiology of stroke after TAVI is multifactorial and includes embolism of valvular material during balloon valvuloplasty, device manipulation across an atheromatous aorta, and atrial fibrillation. ${ }^{19}$ Multiple strategies to reduce periprocedural stroke have been attempted including direct stenting, avoidance of pre- or post-dilation, use of cerebral protection devices and different antithrombotic regimens..$^{20,21}$ Currently, randomised trials are underway to determine whether cerebral protection devices are useful in reducing periprocedural stroke. ${ }^{22}$

Conduction abnormality is another common event following TAVI. The reported rate of permanent pacemaker implantation to treat highgrade heart block varies from $10 \%$ to $30 \%$ and it depends very much on type and implantation depth of the device. ${ }^{23-26}$ The rate reported in the US CoreValve pivotal trial was $20 \%$ at 1 month and $22 \%$ at 1 year. ${ }^{10}$ The permanent pacemaker implantation rate in our cohort was $12.5 \%$ with the majority of our cases having a self-expandable valve. In our cohort, most pacemakers were implanted earlier on in the study period when we were more cautious about treating post-procedural conduction abnormalities.

Major vascular complications occurred in approximately $6 \%$ of patients in the US CoreValve pivotal trial and $11 \%$ in PARTNER 1 trial. ${ }^{9,10}$ Rates of major vascular complications in different observational and randomised trials range from $5 \%$ to $17 \%{ }^{27}$ The lower rate in the US CoreValve pivotal trial can be explained by the smaller size of the introducer sheath for CoreValve (18 Fr) compared with the much bigger 22-24 Fr sheath for the firstgeneration SAPIEN device in the PARTNER 1 trial. ${ }^{9}$ For the same reason and the relative smaller size of peripheral vessels in an Asian population, we would expect a higher rate of vascular complications. Indeed, the major vascular complication rate in our cohort was 8.9\%, which is compatible with the worldwide standard. This is the result of our comprehensive use of CT angiogram for all cases from the beginning of the cohort to delineate the size of the peripheral vessels and better plan of procedural strategies.

Overall, the success of the procedure depends not only on the technical requirement in a very highrisk group of patients but also a comprehensive, multidisciplinary team approach. This 'heart team' approach is the cornerstone of the rapidly developing field of structural heart intervention and preferred strategies in dealing with anticipated complications. ${ }^{27}$

After the success in treating high-risk patients with aortic stenosis, the recently published PARTNER 2 trial evaluated TAVI and SAVR in patients with intermediate surgical risk. It randomised patients with intermediate surgical risk to either TAVI or SAVR; TAVI was non-inferior to SAVR in terms of all-cause mortality and disabling stroke at 2 years $(19.3 \%$ in TAVI group vs $21.1 \%$ in SAVR group; $\mathrm{P}=0.25) .{ }^{28}$ Another major trial testing TAVI in intermediate-risk patients, the SURTAVI Trial (ClinicalTrials.gov number NCT01586910), has completed patient recruitment and the results will be available very soon.

\section{Limitations}

The limitations of the current study include the relatively small sample size and a single-centre early experience. The technology is evolving and loweror intermediate-risk patients are being treated in various clinical trials. With an increasing awareness of the disease and referrals from around the territory, the population being treated is expected to increase in the coming years.

\section{Conclusions}

The technique TAVI has been developed as an alternative treatment for patients with symptomatic severe aortic stenosis who are deemed inoperable or high risk for surgery. It has been proven in major randomised controlled trials to have an acceptable complication rate and durability in the medium term. Our results are very promising and comparable with those of major clinical trials. Long-term clinical outcomes should be diligently monitored.

\section{Declaration}

All authors have disclosed no conflicts of interest.

\section{References}

1. Women and men in Hong Kong-key statistics. 2015 Edition. Available from: http://www.statistics.gov.hk/pub/ B11303032015AN15B0100.pdf. Accessed 26 Jun 2016. 
2. Nkomo VT, Gardin JM, Skelton TN, Gottdiener JS, Scott CG, Enriquez-Sarano M. Burden of valvular heart diseases: a population-based study. Lancet 2006;368:1005-11.

3. Nishimura RA, Otto CM, Bonow RO, et al. 2014 AHA/ ACC guideline for the management of patients with valvular heart disease: a report of the American College of Cardiology/American Heart Association Task Force on Practice Guidelines. J Am Coll Cardiol 2014;63:e57-185.

4. Vahanian A, Alfieri O, Andreotti F, et al. Guidelines on the management of valvular heart disease (version 2012): the joint task force on the management of valvular heart disease of the European Society of Cardiology (ESC) and the European Association for Cardio-Thoracic Surgery (EACTS). Eur J Cardiothorac Surg 2012;42:S1-44.

5. Turina J, Hess O, Sepulcri F, Krayenbuehl HP. Spontaneous course of aortic valve disease. Eur Heart J 1987;8:471-83.

6. Kvidal P, Bergström R, Hörte LG, Ståhle E. Observed and relative survival after aortic valve replacement. J Am Coll Cardiol 2000;35:747-56.

7. Kvidal P, Bergström R, Malm T, Ståhle E. Long-term follow-up of morbidity and mortality after aortic valve replacement with a mechanical valve prosthesis. Eur Heart J 2000;21:1099-111.

8. Bouma BJ, van Den Brink RB, van der Meulen JH, et al. To operate or not on elderly patients with aortic stenosis: the decision and its consequences. Heart 1999;82:143-8.

9. Leon MB, Smith CR, Mack M, et al. Transcatheter aorticvalve implantation for aortic stenosis in patients who cannot undergo surgery. N Engl J Med 2010;363:1597-607.

10. Adams DH, Popma JJ, Reardon MJ, et al. Transcatheter aortic-valve replacement with a self-expanding prosthesis. N Engl J Med 2014;370:1790-8.

11. Smith CR, Leon MB, Mack MJ, et al. Transcatheter versus surgical aortic-valve replacement in high-risk patients. N Engl J Med 2011;364:2187-98.

12. Miller DC. TAVI has a limited role in the treatment of AS. American Association of Thoracic Surgery 2012 Annual Meeting; 2012 Apr 29; San Francisco, United States.

13. Gilard M, Eltchaninoff H, Lung B, et al. Registry of transcatheter aortic-valve implantation in high-risk patients. N Engl J Med 2012;366;1705-15.

14. Lerakis S, Hayek SS, Douglas PS. Paravalvular aortic leak after transcatheter aortic valve replacement: current knowledge. Circulation 2013;127:397-407.

15. Généreux P, Head SJ, Hahn R, et al. Paravalvular leak after transcatheter aortic valve replacement: the new Achilles' heel? A comprehensive review of the literature. J Am Coll Cardiol 2013;61:1125-36.
16. Kodali SK, Williams MR, Smith CR, et al. Two-year outcomes after transcatheter or surgical aortic-valve replacement. N Engl J Med 2012;366:1686-95.

17. Eggebrecht $\mathrm{H}$, Schmermund $\mathrm{A}$, Voigtländer T, Kahlert P, Erbel R, Mehta RH. Risk of stroke after transcatheter aortic valve implantation (TAVI): a meta-analysis of 10,037 published patients. EuroIntervention 2012;8:129-38.

18. Herrmann HC. SAPIEN 3: Evaluation of a balloonexpandable transcatheter aortic valve in high-risk and inoperable patients with aortic stenosis with aortic TCT. San Francisco 2015 Oct 15.

19. Mastoris I, Schoos MM, Dangas GD, Mehran R. Stroke after transcatheter aortic valve replacement: incidence, risk factors, prognosis, and preventive strategies. Clin Cardiol 2014;37:756-64.

20. Ghanem A, Naderi AS, Frerker C, Nickenig G, Kuck KH. Mechanisms and prevention of TAVI-related cerebrovascular events. Curr Pharm Des 2016;22:1879-87.

21. Schmidt $T$, Schlüter $M$, Alessandrini $H$, et al. Histology of debris captured by a cerebral protection system during transcatheter valve-in-valve implantation. Heart 2016;102:1573-80.

22. Kodali S. Cerebral embolic protection devices: Sentinel dual filter device. Update of US Pivotal Clinical Trial. TCT 2015; 2015 Oct 11-15; San Francisco, United States.

23. Webb JG, Altwegg L, Boone RH, et al. Transcatheter aortic valve implantation: impact on clinical and valve-related outcomes. Circulation 2009;119:3009-16.

24. Piazza N, Grube E, Gerckens U, et al. Procedural and 30-day outcomes following transcatheter aortic valve implantation using the third generation $(18 \mathrm{Fr})$ corevalve revalving system: results from the multicentre, expanded evaluation registry 1-year following CE mark approval. EuroIntervention 2008;4:242-9.

25. Jilaihawi H, Chin D, Vasa-Nicotera M, et al. Predictors for permanent pacemaker requirement after transcatheter aortic valve implantation with the CoreValve bioprosthesis. Am Heart J 2009;157:860-6.

26. Kanmanthareddy A, Buddam A, Sharma S, et al. Complete heart block after transcatheter aortic valve implantation: a meta-analysis. Circulation 2014;130:A15832.

27. Toggweiler S, Leipsic J, Binder RK, et al. Management of vascular access in transcatheter aortic valve replacement: part 2: Vascular complications. JACC Cardiovasc Interv 2013;6:767-76.

28. Leon MB, Smith CR, Mack M, et al. Transcatheter or surgical aortic-valve replacement in intermediate-risk patients. N Engl J Med 2016;374:1609-20. 